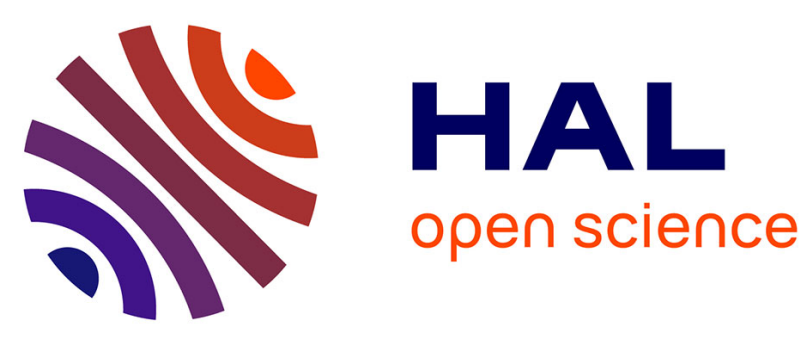

\title{
Learning Process Studies
}

Hans Niedderer, Marion Budde, Damien Givry, Dimitris Psillos, Andrée Tiberghien

\section{To cite this version:}

Hans Niedderer, Marion Budde, Damien Givry, Dimitris Psillos, Andrée Tiberghien. Learning Process Studies. Roser Pinto; Digna Couso. Contributions from science education research, Springer, pp.159171, 2007, 978-1-4020-5031-2. 10.1007/978-1-4020-5032-9_12 . hal-01201763

\section{HAL Id: hal-01201763 \\ https://hal-amu.archives-ouvertes.fr/hal-01201763}

Submitted on 2 Mar 2016

HAL is a multi-disciplinary open access archive for the deposit and dissemination of scientific research documents, whether they are published or not. The documents may come from teaching and research institutions in France or abroad, or from public or private research centers.
L'archive ouverte pluridisciplinaire HAL, est destinée au dépôt et à la diffusion de documents scientifiques de niveau recherche, publiés ou non, émanant des établissements d'enseignement et de recherche français ou étrangers, des laboratoires publics ou privés.

\section{(c) (1) $\$$}

Distributed under a Creative Commons Attribution - NonCommercial| 4.0 International 


\section{Learning process studies}

Niedderer, H. ${ }^{1}$, Budde, M. ${ }^{2}$, Givry, D. ${ }^{3}$, Psillos, D. ${ }^{4}$, Tiberghien, A. ${ }^{3}$

${ }^{1}$ Mälardalens Högskola, Sweden, ${ }^{2}$ Universum Science Center Bremen, Germany,

${ }^{3}$ CNRS-Université Lyon, France, ${ }^{4}$ Aristotle University Thessaloniki, Greece

\section{Introduction}

In 1991, an international workshop held in Bremen was working on "Research in Physics Learning - Theoretical Issues and Empirical Studies" (Duit, Goldberg, Niedderer 1992). The intention of this workshop was to develop a new research goal, which was to study learning processes with data from during the learning process.

The main point, which often makes learning process studies very important and interesting is the following: Students' actual constructions are often different from taught knowledge. In other words: there is a gap between what we teach and what is learnt (McDermott 1991), the knowledge to be taught is different from students' steps of learning (Tiberghien 1997). The students undertake a cognitive development, which leads them towards constructing certain "intermediate conceptions" (see below) corresponding to their cognitive structure (Niedderer 2001).

In this paper, we are presenting some theoretical and methodological issues together with some results from new studies (Givry 2003; Budde 2004).

\section{Theoretical framework}

Conceptions and expressed ideas

Many authors use the term "conception" to denote their basic concept of thinking and learning (see Duit 2004). A conception is seen as a hypothetical set of statements, skills, procedures, that the researcher attributes to one or more students in order to account for students' behaviour in a set of given situations (Tiberghien 1997). Here, we distinguish between two cases:

(1) One is to consider that a conception intends to be part of modelling students' mind. It is a construction of a researcher to describe typical use of elements of knowledge and ways of thinking of students. A conception has to be stable and must appear in more than one context and point in time.

(2) The other is to consider that the researcher infers only ideas, which are expressed in the students' productions without making hypotheses on students' mind (Givry and Roth in press). These inferences will be called "expressed-ideas" to distinguish them from the previous approach.

These two approaches show that, even if the points of view on the students' mind modelling are different, the analysis and the results on learning are compatible and mutually reinforced. Both approaches are inferred from students' productions (utterances, gestures, writing) by the researcher and can show some stability over time (Niedderer 2001) and through several situations (Givry 2003). The set of these situations represent their domain of validity, this domain can be reduced to a single situation or be stable in several situations. In both cases there is a construction of a researcher, which describes the core of several ideas of students in the researchers own words using the most distinctive features of those ideas for this description. This procedure is also aiming at a considerable reduction of data, describing the core of a set of ideas in a set of situations with one conception.

Learning processes

Often, learning processes ${ }^{1}$ can be represented as a sequence of conceptions developed by students during instruction. These conceptions do not exclude each other; a student can have

\footnotetext{
${ }^{1}$ The use of the term process here can be justified by stating that it describes a series of steps, which allow to acquire the scientific taught concepts and then are a student's way of going from initial to final conceptions ("learning pathway").
} 
more than one conception in parallel at the same time (Taber 2000; Petri \& Niedderer 1998 and 2003; Hartmann \& Niedderer 2005). Here conception is taken in the larger sense given previously and is specified in each study. For example; some authors (Petri \& Niedderer; Psillos \& Kariotoglou) use the term "conception" or "concept of a student" to describe a learning process as a series of conceptual changes (Dykstra 1992). Here are typical examples of studies:

The study of Petri \& Niedderer (1998) describes a learning process of one student's atomic model developing during a course in quantum atomic physics (grade 13) with about eighty lessons (figure 1).

\begin{tabular}{|l|c|c|c|}
\hline Carl's first conception & Carl's second conception & Carl's third conception & Carl's fourth conception \\
\hline
\end{tabular}

Figure 1: Learning process of one student's conceptions about the atom (after Petri \& Niedderer 1998)

Psillos \& Kariotoglou (1999) in their study "Teaching fluids: Intended knowledge and students' actual conceptual evolution" describe learning processes of three representative students as a series of concepts of these students (figure 2).

\begin{tabular}{|c|c|c|c|}
\hline $\begin{array}{c}\text { Initial } \\
\text { concept for } \mathrm{P} / \mathrm{F}\end{array}$ & $\begin{array}{c}\text { Refined initial } \\
\text { concept for } \mathrm{P} / \mathrm{F}\end{array}$ & $\begin{array}{c}\text { Scientific } \\
\text { concept for } \mathrm{P} / \mathrm{F}\end{array}$ & $\begin{array}{c}\text { Refined scientific } \\
\text { concept for } \mathrm{P} / \mathrm{F}\end{array}$ \\
\hline $\begin{array}{c}\text { Force }=\text { pressure } \\
\text { "pressure-force model" }\end{array}$ & $\begin{array}{c}\text { Force } \approx \text { pressure, } \\
\text { pressure as a state variable, } \\
\text { force as interaction }\end{array}$ & $\begin{array}{c}\text { Force } \neq \text { pressure, } \\
\mathrm{P}=\mathrm{F} / \mathrm{A} \text { (qualitative) }\end{array}$ & $\begin{array}{c}\text { Force } \neq \text { pressure, } \\
\mathrm{P}=\mathrm{F} / \mathrm{A} \text { (qualitative) } \\
\text { Understanding additivity }\end{array}$ \\
\hline
\end{tabular}

Figure 2: Learning process of one student's conceptions of force and pressure (after Psillos \& Kariotoglou 1999)

Taber (2001) in his case study of conceptual development as competition between alternative conceptions about bonding uses "evolving explanatory principles" as one form of conception to describe a learning process of one student in two years of an A level course in chemistry.

Clement \& Steinberg (2002) in their study "Step-Wise Evolution of Mental Models of Electric Circuits: A 'Learning-Aloud' Case Study" used "evolving explanatory models" - a series of successive modified models - to describe their student's learning process all along a teaching unit.

Givry (2003; part 3 of this paper) uses a slightly different approach to define learning, using the model of "expressed idea", with less generalisations to conceptions. This model considers learning process as "evolution of student's ideas" and identifies three kinds of evolution to describe some aspects of learning:

- A student expresses a new idea.

- A student increases the domain of validity of an idea.

- A student establishes a link between several ideas and develops a network.

This last type of evolution is very similar to learning as forming new conceptions, whereas the former two aspects can be seen as first important steps towards learning.

Budde (2004; part 4 of this paper) understands learning to be the development or change of conceptions as well as the modification of the status and strength (Petri \& Niedderer 1998) of co-existing conceptions. Learning is described as the interaction between the cognitive system of the student (the student's ideas and conceptions) and the contents of the learning environment. She uses both "idea" and "conception" to describe learning. An idea is a description with which a single statement of the student can be explained. A conception is able to explain two or more student's statements. 
Intermediate conceptions

The idea of "intermediate notions" or "intermediate conceptions" as building of bridges between children science or formal science goes back to Driver's work in 1989 (Taber 2001, 735). It has been used in similar ways by many authors. Galili et al. (1993) used the expression "hybrid knowledge". We stated earlier that we should expect actual constructions being often different from intended conceptions by the teacher, even if they are influenced by the taught knowledge. Often, these resulting actual constructions are described as intermediate conceptions or intermediate explanatory models, and as unexpected or not at all intended by the teacher. That means that they should be seen as a cognitive development using students' prior conceptions (and other cognitive tools) to make sense of the new teaching content (Niedderer 2001). So, intermediate conceptions are conceptions, which are different from prior conceptions, still different from the intended conceptions and most likely to be developed in students' learning processes.

The term "intermediate conception" is used by Petri \& Niedderer (1998) to describe Carl's second conception in figure 1 as his own construction; this model of the atom was not at all taught by the teacher. But also the later conceptions should be seen as "intermediate" in the sense that students' constructions are still different from the teachers' intention. Psillos \& Kariotoglou (1999) in their study also use the term "intermediate conception" to describe especially their second conception in figure 2. These authors write: "An important indication from the data shows that an intermediate, refined, initial conception was constructed too, ...". Taber (2001) writes about his student's "Coulombic forces explanatory principle": "Although such ideas were formally incorrect, they had greater potential for being developed into explanations in terms of physical forces: i.e. they were able to act as intermediate conceptions on an appropriate conceptual trajectory." Clement and Steinberg (2002) in their study use also a similar term "intermediate explanatory model" to describe their findings. They write: "intermediate explanatory models utilizing dynamic imagery are the form of her new conceptual understanding".

Some methodological issues of learning process studies

Using data from during the teaching and learning processes is perhaps the critical instance of learning process studies. All studies reported followed single students, either one, two or three. In the new studies reported here, Givry (2003) and Budde (2004) follow two students each. Of course we need to know about the learning processes of all students in a class. But the amount of qualitative data seems not to allow this. Clement and Steinberg (2002) have been very explicit on this problem: "Attempts to track learning processes at this level of detail in groups of students have been frustrating for us because we do not hear enough from each student to follow the process without large gaps." Then they argue that nevertheless these studies could be of some value: " ... such studies can be an important source for generating grounded hypotheses about learning processes that have a substantial initial level of plausibility and that are worth investigating in larger samples." Perhaps, this problem can be solved best with a combination of a qualitative learning process study and a quantitative evaluation study.

Givry (2003; part 3 of this paper) collected, during one month, different types of data about students' point of view on gas behaviours. This data including: (1) videotaped lessons, (2) videotaped interviews and (3) written questionnaires. Student's learning processes are studied through the videos and student's ideas about gas are reconstructed by the researcher based on: (a) the context of the situations and (b) student's: speech, gestures, manipulation, and written works.

In the study of Budde (2004; part 4 of this paper) the data collected consisted mainly of audio-tape records of the regular school lessons. Before and directly after instruction the students provided written responses to questions probing their views and understanding of 
atomic models. To investigate the longer term stability of the students' conceptions, control interviews were also held two years after the end of the instruction. Alongside the evaluation of the learning of the full cohort of students (26 students in total), exploratory case-studies, focussing on two 18-years old students, were carried out to obtain a better understanding of the influence of the teaching on the development of the individual student's conceptions.

What is the relation between teaching and learning?

This is finally the most important question. Givry (2003; part 3 of this paper) uses the French concept of "milieu" to study the factors, which support the evolution of student's ideas. It is composed of several elements with which students could interact to learn (Brousseau 1998). Based on a socio-constructivist approach and literature from didactics of physics, the milieu is defined with three kinds of interaction (figure 3):

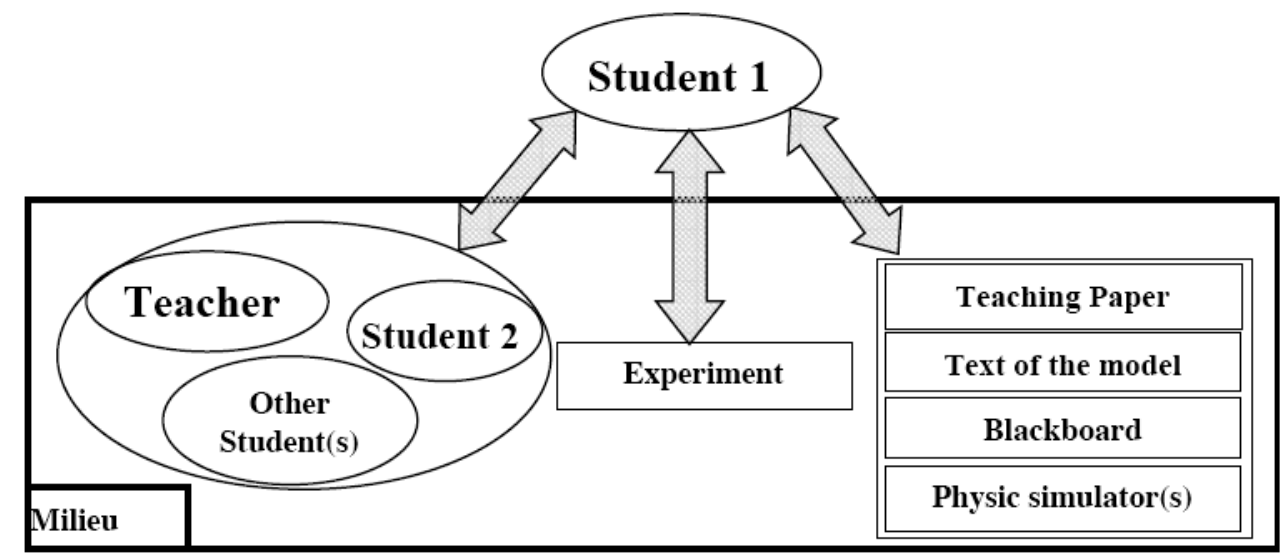

Figure 3: Milieu composed by different elements

(social, experimental, teaching material), which student could interact to learn.

Then the influence of teaching is studied through elements (social, experimental, teaching material), which are explicitly used by students to support their ideas.

Budde (2004; part 4 of this paper) uses a notion from von Glasersfeld (1992) to describe the relation between teaching and learning as a resonance between learning environment and students' mind. Hypotheses about resonances between certain elements of taught content as part of the learning environment and the evolution of students' conceptions as part of their cognitive system are formulated as teaching hypotheses. By carefully following the talk of individual students and relating it to the content of teaching, it is possible to test these teaching hypotheses. Observations are made to ascertain whether, and after how many repetitions and discussions, the students construct the intended conceptions. In this way, the opportunities and difficulties presented by different teaching approaches can be evaluated against each other, and principled decisions about the planning and design of teaching can be made. The analysis was based on definitions of different types of resonances (see Budde 2004). Here for illustration, we present a few of the defined categories:

Congruent resonance: the student constructs in his own independent thinking conceptions, which are essentially equal to the content presented in the learning environment before.

Disgruent resonance: the student constructs in his own independent thinking conceptions, which are essentially different to the content presented in the learning environment before.

Spontaneous (congruent) resonance: Already after the first presentation of a certain content a congruent resonance is happening.

The results are summarised diagrammatically (see figure 5) in such a way that differences between the contents that are taught (on the left side) and the conceptions that the students construct (on the right side) are made explicit. 


\section{Evolution of student's ideas about gases}

\section{Context of the Research}

The purpose of our study is to give some elements to follow students' conceptual change and the factors that support this change during a teaching unit about gas behaviours. Providing empirical results from a longitudinal study in French Physic classroom, we answer the questions: How do student's ideas about gas evolve during a teaching unit? What are the elements that support this evolution?

Theoretical Background

As presented above, a model "expressed idea" has been developed based on a previous theoretical model (Minstrell 1992). Furthermore, we use the French concept of "milieu" (Brousseau, 1998) to study the elements of the class, which support the evolution of students' ideas. (Figure 3).

School Context and Participants

A group of physics teachers and researchers (including both authors) designed the curriculum to be taught over a one-month period (6 lessons) for students at the upper secondary school level (equivalent to tenth grade [15-year-old students]). The teaching unit consisted of six lessons: two sessions ( 1 hour, whole class) and four laboratory sessions (1 hour 30, halfclass). It adopted socio-constructivist approach with respect to three main dimensions: (a) modelling activity (Tiberghien, 2000), (b) semiotic registers (Duval, 1995), and students' conception of a gas (i.e. Benson \& al. 1993). The purpose of the unit was to allow students to use (a) macroscopic variables (pressure, volume, temperature and quantity of matter), and (b) their interpretation at the microscopic level (molecules' collisions and velocity) for describing and explaining gas behaviour.

Methodology

Different types of data sources were collected including videotaped interviews and lessons as well as questionnaires sampling student responses to questions about gas behaviour. All in all, the database comprises 420 questionnaires, one-hour taped interviews with 14 students prior to and after the unit in videotaped sessions, 48 hours of classroom video featuring the same 14 students, with two students particularly observed, and approximately 160 pages work sheets. Following the precepts of the Learning Process Studies (Niedderer et al. 1992), fourteen students were videotaped continuously during one month of the lessons in classroom. We selected video extracts based on two observable criteria: (1) use of words about gas by teacher or students (i.e. air, gas, molecules) or (2) experiment handling used by students. We transcribe each video extract and our transcription included: (a) the context and (b) a student's speech, gestures, manipulation, and written works. Then, we constructed a student's ideas about gas expressed through: (a) written language and (b) oral language: speech, gestures and salient elements of the setting. For each idea, we tried to identify, what elements of the milieu (social, experimental, teaching material) are explicitly used by the student to support his/her idea.

$\underline{\text { Results }}$

With our methodology, we followed the different kinds of evolution of two students' ideas about gases (called Anne and Ellen) during the entire teaching unit. We identify several explicit elements of the milieu, which support this evolution.

Express a new idea. Student expresses a new idea through language: oral or written. In the case of oral language, idea could be expressed through: speech, gestures and salient element of the setting; e.g. Anne expresses that "there is no air in an open bottle" by using simultaneously these three modalities (figure 4). New ideas about gases are expressed 12 times for Anne and 9 times for Ellen during the whole teaching unit. This kind of evolution could be supported by some specific elements of the milieu. Indeed, new ideas about the 
meaning of words (like macroscopic pressure) are supported essentially by the teacher discourse and the teaching paper.

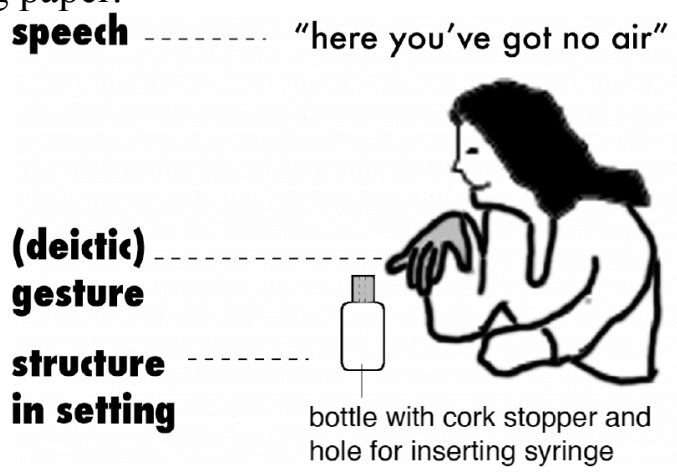

Figure 4: Anne's idea expressed simultaneously by talk ("here you've got no air"), gestures (her hand is pointing to the open bottle), and semiotic resources in the setting (glossed as "the open bottle").

Furthermore, the text about the model of a gas supports new ideas about the properties of gas (i.e.: homogenous distribution, choc of molecules).

Increasing the domain of validity of an idea. This kind of evolution appears when a student expresses the same idea in another situation. A situation is new, when (1) the question changes (e.g. a question about the pressure of gas and a question about the gas distribution) or (2) the material (objects or events) changes (e.g. use of an open bottle, then use of a balloon). This kind of evolution appears 19 times with Anne and 20 times with Ellen during the teaching unit. This kind of evolution is more frequent for the two students, compared to « express a new idea » or " make a link between ideas ». However, no specific element of the milieu seems to support this kind of evolution; each element (social, experimental, teaching material) of the milieu seems to support the increase of the domain of validity.

Decreasing the domain of validity of an idea. This kind of evolution is given, if a student realises that an idea doesn't work in a specific situation and stops to use it. This kind of evolution is particularly important, it appears however only 1 time with Anne and 3 times with Ellen. Decreasing the domain of validity appears only a few times during the teaching unit and necessitates the simultaneous use of several elements of the milieu (essentially discussion between students and manipulation of experiment).

Establishing a link between several ideas and develop a network. This link can be expressed by a student through the language: oral or written; e.g. Anne wrote: There is space between molecules, consequently we can add air inside the bottle. Here, she makes a link between two ideas: (1) «there is space between molecules » and (2) «we can add air inside the bottle ». This kind of evolution is used 9 times with Anne and 7 times with Ellen during the teaching unit. This kind of evolution is supported essentially by the manipulation of experiment.

Conclusion

The results show that the principal evolution is the increase of the domain of validity of an idea. The teachers, through different exercises, implicitly support this kind of evolution. However, this kind of evolution is rarely assessed. Consequently, we propose to design teaching unit, in which the same concepts are studied in several situations. Furthermore, our results about the elements of the milieu showed that each kind of elements could support the evolution of students' ideas. Consequently, we propose to make the maximum of elements available to students. Other results show that the discussions between students are particularly important, because they support (a) the construction of new ideas about all the aspects of gas and (b) all the other kinds of evolution.

\section{Influences of taught content on student learning in quantum atomic physics}


This study was a part of a project to evaluate the Bremen teaching approach in quantum atomic physics (Niedderer and Deylitz 1999). The teaching approach uses a more abstract probability density interpretation alongside with a visual charge cloud/electronium interpretation of the $\psi$-function for bound states of an atom (Herrmann 2000). Implicit in the approach to teaching the charge cloud/electronium model were a number of teaching hypotheses which were developed from an analysis of previous research in various domains including quantum atomic physics.

When teaching the probability model two main learning problems emerge (e.g. Bethge 1992, Fischler and Lichtfeldt 1992, Mueller and Wiesner 1999):

- Students tend to retain their preconceptions (mainly planetary orbit or shell conceptions) or revert to their preconceptions after teaching, thus there is no long-term learning effect.

- Students construct alternative conceptions, which differ significantly from the intended models. In particular, they retain the belief that the electrons are moving on trajectories in the atom.

The introduction of the charge cloud/electronium model bases on the following starting hypothesis: The visual appearance of the charge cloud/electronium model may support the acceptance of a quantum atomic model, based on the Schroedinger equation.

In the following the results concerning this starting hypothesis are presented for the two observed students Thomas and Klaus.

For Thomas the charge cloud/electronium model shows a congruent resonance from the early stages of teaching. After the pre-questionnaire, in which the models were introduced briefly, Thomas took the initiative in using the charge cloud/electronium model in an intuitive way.

Although Klaus preferred a probability model at the beginning, he finally switched to the charge cloud/electronium model. After the probability and charge cloud/electronium models were discussed in detail, both Thomas and Klaus, and all their class-mates, agreed that they preferred the charge cloud/electronium model. One repeatedly expressed reason, from both students, for this preference of the charge cloud/electronium model focussed on its substantial, visual appearance. Thus Thomas commented:

"Me too. I also rather prefer the model of Friedrich Herrmann. It is more descriptive. It is easier to imagine. In this model, the electron does not disappear and appear again without one knowing, how it managed this [like in the probability model]."

For all nine students in the class, the charge cloud/electronium model achieved a high acceptance. Furthermore both Klaus and Thomas were still able to outline the charge cloud/electronium model in the control-interviews two years after the end of the instruction, which proves the stability of the charge cloud/electronium conception.

There were two further aspects of the charge cloud/electronium model, which were frequently and spontaneously referred to by both students and thus constituted a strong congruent resonance for the students. These conceptions achieved a high acceptance for the students and were stable. The two aspects are:

- Concerning the charge distribution in the ground state (1s-state): The charge density is the highest at the nucleus and decreases to a higher radius. ${ }^{2}$

- Concerning the change of the charge distribution in the case of a transition between two stationary states: The charge will move away from the nucleus (the charge will be distributed more distant from the nucleus) if energy is added.

The majority of all students (17 of 26) mentioned spontaneously the decreasing charge density to a higher radius in the post-questionnaire. It is assumed that the high acceptance

\footnotetext{
${ }^{2}$ Although this description is correct for all states (if the region with nodal areas is disregarded), it is assumed that the students especially imagine the $1 \mathrm{~s}$-state. One indicator for this is that the students always draw the $1 \mathrm{~s}-$ state when asked for their image of an atom.
} 
outcome results from the fact that the new ideas build upon students' preconceptions. Many explanations were given by students for this characteristic trait of the charge distribution.

The findings for Klaus and Thomas are summarised in figure 5. They explained the charge distribution in terms of attractive or repulsive electrostatic forces. The students also used analogies between atoms and their ideas about the atmosphere or water, where the density decreases with height or increases with depth. The effect of the electrostatic force is seen as being equivalent to the effect of pressure, which is interpreted as compression: the higher the force or pressure, the more the substance is compressed, the higher is its density.

The main argument for the characteristic charge distribution given by the two students is, that it is simply logical that the charge is distributed like the electrostatic force or field.

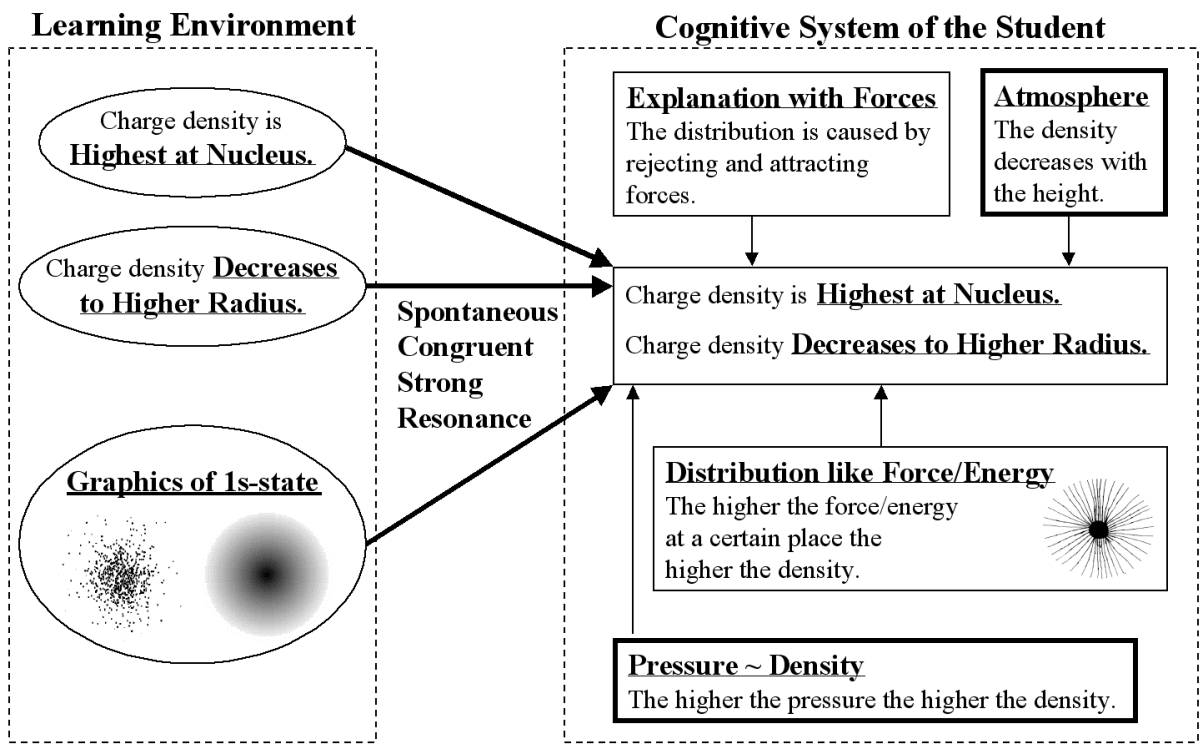

Figure 5: Examples of spontaneous congruent strong resonances

These results lead to the following final hypotheses:

The visual appearance of the charge cloud/electronium model may support the acceptance of a quantum atomic model.

The specific distribution of the charge density in the ground state and the increased radius of higher states may be plausible to students, which increases the acceptance of the new atomic models.

It appears that if the teaching focuses on the aspects that are plausible to the students (distribution in the 1s-state; the uptake of energy causes a more distant distribution) and easily to visualize (charge cloud/electronium), the students accept an atomic model that bases on the solutions of the Schroedinger equation and do not give up their new quantum atomic conception after instruction.

\section{Conclusions and discussion}

Learning process studies have been and are carried out for several years by researchers who employ different approaches and have different assumptions about teaching, learning and understanding science. Despite methodological and substantial differences it appears that these researchers share implicitly or explicitly certain assumptions, that are reflected in the present and the previous studies. One assumption, which has already been stated, is that teaching does not necessarily involve learning by students; a second assumption is that advances in our understanding of teaching learning interactions can be considerably facilitated by developing models of teaching and learning process; a third assumption is that such models can draw on individual students conceptual evolution during a teaching learning sequence. The advantage of such a modelling process is two fold. At first, it provides for dynamic aspect of students' conceptual evolutions leading to detailed descriptions of different 
states and therefore to clarifications of what is involved in learning science in specific domains. Second, it relates such evolutions to certain aspects of the respective learning environment notably the local demands on students during the course of a teaching sequence. In other words, it allows for developing grounded hypotheses and humble theories about domain specific learning in relation to teaching. This allows for the development of local hypothesis concerning particular aspects of teaching leading not only to modelling of learning but to modelling of teaching, which at times is rather neglected in published studies.

Having said the above it appears that there are certain limitations, at least at present, which need to be dealt with in future research. One is the development of a common terminology, which is shared by researchers and applied to describe students' developments; a second is that the units of analysis of individual student development is subject to contextual constraints and a third is that the construction of students' intermediate steps involves craft expertise by researchers, and therefore is difficult to be validated in different contexts. Such limitations are appear in several published investigations in science education research. They are more pertinent though for learning processes studies aiming at gradually developing consensus models about teaching and learning.

Despite such limitations the presented studies provide considerable insights not only on students' learning but also on modifying the corresponding teaching in the domain of teaching gases and quantum atomic physics, as in previous topics. By modifying we mean either eliminating or constructing activities and steps, which are dynamically adapted to students constructions. One consequence could be that certain teaching aims are not realistic and could be adapted to what seems learnable as stepping stones (Brown and Clement 1992, Tiberghien 1997, Psillos and Kariotoglou 1999). Another consequence would be to find hypotheses for learning process studies for larger groups (Clement and Steinberg 2002). Such information would be valuable for research based design of teaching in a number of domains and for guiding future research.

A quite new research idea as introduced in this paper is to determine learning effects of special elements of the learning environment during a learning process and thus helping to improve learning environment by curriculum development.

\section{References}

Benson, D. L., Wittrock, M. C., \& Baur, M. E. (1993). Students' preconceptions of the nature of gases. Journal of Research in Science Teaching, 30, 587-597.

Bethge, T. (1992): Schülervorstellungen zu grundlegenden Begriffen der Atomphysik. In: Fischler, H.(Hrsg.): Quantenphysik in der Schule, Kiel: IPN, 215-233.

Brousseau G. (1998) Théorie des situations didactiques, Grenoble: La Pensée Sauvage éditions.

Brown, D.E., Clement, J. (1992). Classroom teaching experiments in mechanics. In: Duit, R., Goldberg, F., Niedderer, H.: Research in physics learning: Theoretical issues and empirical studies. Kiel: IPN, 380-397

Budde, M. (2004). Lernwirkungen in der Quanten-Atom-Physik. Fallstudien über Resonanzen zwischen Lernangeboten und SchülerInnen-Vorstellungen. (Learning effects in quantum atomic physics - case studies on resonances between content-specific elements of the learning environment and the evolution of students' conceptions). Doctoral dissertation University of Bremen. In H. Niedderer, H. Fischler (eds): Studien zum Physiklernen, Band 31. Berlin: Logos

Budde, M., Niedderer, H., Scott, P., Leach, J. (2002). The quantum atomic model 'Electronium': a successful teaching tool. Physics Education, 37, 204-210

Clement, J. J., Steinberg, M. S. (2002). Step-Wise Evolution of Mental Models of Electric Circuits: A "Learning-Aloud" Case Study. The Journal of the Learning Sciences 11(4), 389-452

Duit, R. (2004). Bibliography - STCSE. Students' and Teachers' Conceptions and Science Education1. Kiel: IPN. See http://www.ipn.uni-kiel.de/aktuell/stcse/stcse.html

Duit, R., Goldberg, F., Niedderer, H. Eds. (1992). Research in Physics Learning - Theoretical Issues and Empirical Studies. Kiel: IPN

Duval R. (1995). Sémiosis et pensée humaine, registres sémiotiques et apprentissages intellectuels. Ed Peter Lang.

Dykstra, D. (1992). Studying conceptual change: Constructing new understandings. In R. Duit, F. Goldberg, H. Niedderer (eds.): Research in Physics Learning - Theoretical Issues and Empirical Studies. Kiel: IPN, 40-58 
Fischler, H.; Lichtfeldt, M. (1992): Modern Physics and Students' Conceptions. International Journal of Science Education 14(2), 181-190.

Galili, I., Bendall, S., Goldberg, F.M. (1993). The effects of prior knowledge and instruction on understanding image formation. Journal of Research in Science Teaching 30, 3, 271-301

Givry, D. (2003). Étude de l'évolution des idées des élèves de seconde durant une séquence d'enseignement sur les gaz. (Study of the evolution of students' knowledge during a teaching sequence on gases at the upper secondary school level). Doctoral dissertation, Université Lyon II.

Givry, D. \& Roth, W.-M. (in press). Toward a New Idea of Conceptions and Conceptual Change: The Interplay of Talk, Gestures, and Semiotic Resources in the Setting. Journal of Research in Science Teaching.

Hartmann, S., Niedderer, H. (2005). Parallel Conceptions and Learning in the Domain of Force and Motion. In K. Boersma, H. Eijkelhof, O. de Jong, M. Goedhart (eds.), Research and the Quality of Education. Dordrecht: Kluwer Academic Publishers

Herrmann, F. (2000): The Karlsruhe Physics Course. European Journal of Physics 21, 49-58.

McDermott, L. C. (1991). Millikan lecture 1990: What we teach and what is learned: Closing the gap. American Journal of Physics 59(4): 301-315

Minstrell, J. (1992). Facets of students' knowledge and relevant instruction. In R. Duit, Goldberg, F., Niedderer, H. (Ed.), Research in physics learning: Theoretical issues and empirical studies. Kiel: IPN. 110-128.

Mueller, R.; Wiesner, H. (1999): Students' Conceptions of Quantum Physics. In: Zollman, D. (ed.): Research on Teaching and Learning Quantum Mechanics. Papers presented at the annual meeting of the National Association for Research in Science Teaching, March 1999, 20-22.

(Found 2005 at http://www.phys.ksu.edu/perg/papers/narst/).

Niedderer, H., Goldberg, F., Duit, R. (1992). Towards learning process studies: A review of the workshop on research in physics learning. In R. Duit, F. Goldberg, H. Niedderer (eds.): Research in Physics Learning Theoretical Issues and Empirical Studies. Kiel: IPN, 10-28

(Found 2005 at http://didaktik.physik.uni-bremen.de/niedderer/)

Niedderer, H., Deylitz, S. (1999). Evaluation of a New Approach in Quantum Atomic Physics in high school. In D. Zollman (ed.): Research on teaching and Learning quantum mechanics. Papers presented at the annual meeting National Association for Research in Science Teaching, March, 1999, 23-27

(Found 2005 at http://www.phys.ksu.edu/perg/papers/narst/).

Niedderer, H. (2001): Physics Learning as Cognitive Development. In: Evans, R. H.; Andersen, A. M.; Sørensen, H. (eds.), Bridging Research Methodology and Research Aims. Student and Faculty Contributions from the 5th ESERA Summerschool in Gilleleje, Denmark. The Danish University of Education, 397-414. (Found 2005 at http://didaktik.physik.uni-bremen.de/niedderer/)

Petri, J., and Niedderer, H. (1998). A learning pathway in high-school level quantum atomic physics. International Journal of Science Education, 20 (9), 1075-1088.

Petri, J., Niedderer, H. (2003). Atomic Physics in Upper Secondary School: Layers of Conceptions in Individual Cognitive Structure. In: Psillos, D., Kariotoglou, P., Tselfes, V., Hatzikraniotis, E., Fassoulopoulos, G., Kallery, M., (eds.): Science Education in the Knowledge-Based Society. Dordrecht: Kluwer Academic Publishers 137-144

Psillos, D., Kariotoglou, P. (1999). Teaching fluids: Intended knowledge and students' actual conceptual evolution. International Journal of Science Education 21(1): 17-38

Taber, K. S. (2000). Multiple frameworks?: Evidence of manifold conc eptions in indiv idual cognitive structure. International Journal of Science Education, VOL. 22, NO. 4, 399 - 417

Taber, K. S. (2001). Shifting sands: A case study of conceptual development as competition between alternative conceptions. International Journal of Science Education, 23(7), 731-754.

Tiberghien, A.(1997). Learning and teaching: Differenciation and Relation. Research in Science Education, 27(3), 359-382

Tiberghien, A. (2000). Designing teaching situations in the secondary school. In R. Millar, J. Leach and J. Osborne (Editors): Improving science education: the contribution of research. Buckingham, UK: Open University Press. 27-47

von Glasersfeld, E. (1992): A Constructivist View of Learning and Teaching. In R. Duit, F. Goldberg, H. Niedderer (Eds.): Research in Physics Learning: Theoretical Issues and Empirical Studies. Proceedings of an International Workshop in Bremen, Kiel: IPN, 29-39.

${ }^{\mathrm{i}}$ The teaching unit can be download at URL: http://pegase.inrp.fr/ 